OPEN ACCESS

Edited by:

Christian Gonzalez-Billault,

University of Chile, Chile

Reviewed by:

Avner Cnaani,

Agricultural Research Organization (ARO), Israel Devin Wahl,

Colorado State University, United States

*Correspondence: Andre P. Seale seale@hawaii.edu

Specialty section:

This article was submitted to Molecular Mechanisms of Aging, a section of the journal Frontiers in Aging

Received: 03 March 2021 Accepted: 12 May 2021

Published: 09 June 2021

Citation:

Inokuchi $M$, Yamaguchi $Y$, Moorman BP and Seale AP (2021) Age-Dependent Decline in Salinity

Tolerance in a Euryhaline Fish.

Front. Aging 2:675395.

doi: 10.3389/fragi.2021.675395

\section{Age-Dependent Decline in Salinity Tolerance in a Euryhaline Fish}

\author{
Mayu Inokuchi ${ }^{1}$, Yoko Yamaguchi ${ }^{2}$, Benjamin P. Moorman ${ }^{3}$ and Andre P. Seale ${ }^{3,4 *}$ \\ ${ }^{1}$ Department of Aquatic Bioscience, Graduate School of Agricultural and Life Sciences, University of Tokyo, Tokyo, Japan, \\ ${ }^{2}$ Institute of Agricultural and Life Sciences, Academic Assembly, Shimane University, Matsue, Japan, ${ }^{3}$ Hawai'i Institute of Marine \\ Biology, University of Hawai'i, Kaneohe, HI, United States, ${ }^{4}$ Department of Human Nutrition, Food and Animal Sciences, \\ University of Hawai'i at Mānoa, Honolulu, HI, United States
}

Euryhaline teleost fish are characterized by their ability to tolerate a wide range of environmental salinities by modifying the function of osmoregulatory cells and tissues. In this study, we experimentally addressed the age-related decline in the sensitivity of osmoregulatory transcripts associated with a transfer from fresh water (FW) to seawater (SW) in the euryhaline teleost, Mozambique tilapia, Oreochromis mossambicus. The survival rates of tilapia transferred from FW to SW were inversely related with age, indicating that older fish require a longer acclimation period during a salinity challenge. The relative expression of $\mathrm{Na}^{+} / \mathrm{K}^{+} / 2 \mathrm{Cl}^{-}$cotransporter 1a (nkcc1a), which plays an important role in hyposmoregulation, was significantly upregulated in younger fish after SW transfer, indicating a clear effect of age in the sensitivity of branchial ionocytes. Prolactin (Prl), a hyperosmoregulatory hormone in O. mossambicus, is released in direct response to a fall in extracellular osmolality. Prl cells of 4-month-old tilapia were sensitive to hyposmotic stimuli, while those of $>24$-month-old fish did not respond. Moreover, the responsiveness of branchial ionocytes to Prl was more robust in younger fish. Taken together, multiple aspects of osmotic homeostasis, from osmoreception to hormonal and environmental control of osmoregulation, declined in older fish. This decline appears to undermine the ability of older fish to survive transfer to hyperosmotic environments.

Keywords: osmoregulation, osmoreception, fish, age, survival, salinity tolerance, gill, prolactin

\section{INTRODUCTION}

The maintenance of body fluid osmolality and cellular sensitivity to osmotic and endocrine stimuli are fundamental components of homeostasis that become compromised with age in vertebrates. Osmoreception, the first step in osmoregulation, involves the integration between cellular mediators of osmotic changes, and effectors, typically hormones, capable of acting systemically to restore salt and water balance (Grau et al., 1994; Bourque and Oliet, 1997; Seale et al., 2012b). Osmoregulation, in turn, depends on a balance between the intake and output of ions and water. In humans, aging is often characterized by reduced homeostatic capacity, and disturbances in sodium and water balance (Rolls and Phillips, 1990; Pomatto and Davies, 2017). A number of studies have shown age-related differences in thirst, hypothalamic cellular sensitivity, and osmoregulatory endocrine responses, especially those related to vasopressin release (Robertson and Rowe, 1980; Baylis, 1987; Mack et al., 1994; Lee et al., 1998; Thunhorst et al., 2010; Thunhorst et al., 2011). Dehydration with aging has been attributed to a loss in the ability to concentrate urine (O'Neill and McLean, 1992; Dmitrieva and Burg, 2011) and to a decrease in thirst (Kenney and Chiu, 2001). Furthermore, cellular senescence in osmoregulatory tissues, such as the kidney, is accelerated due to high interstitial $\mathrm{NaCl}$ concentration 
and contributes to the aging-related impairment of salt and water balance (Dmitrieva and Burg, 2007). While some studies have employed fish models to examine how senescence may relate to loss in osmoregulatory capability (Jeffries et al., 2011), little is known on the effects of age on the physiological mechanisms underlying the capacity of organisms to face salinity challenges. While terrestrial vertebrates are constantly exposed to the threat of dehydration due to high respiratory water loss, fishes are more vulnerable to osmotic changes because their body fluids are only separated from water of varying salinities by the thin respiratory epithelia of the gills (Takei et al., 2014). In teleost fish, the gill is considered to be a primary site for monovalent ion regulation, a function that is performed by the kidney in mammals (Evans et al., 2005). To the extent that both organs share many of the molecular mediators of ion transport, studies addressing agedependent osmoregulatory responses of the gill may provide insight into similar mechanisms in humans. Model organisms with compact life spans that live in direct contact with aquatic environments and possess the physiological capacity to tolerate changes in salinity offer unique access for investigating the effects of aging on the endocrine and environmental control of osmoregulation.

Euryhaline teleost fish such as Mozambique tilapia, Oreochromis mossambicus, possess the capacity to tolerate a wide range of salinities. Mozambique tilapia have evolved in continually changing environments that are characterized by tidal changes in salinity spanning fresh water (FW) and seawater (SW) and are able to modify the function of the cells and tissues that regulate salt and water balance (Inokuchi et al., 2015; Moorman et al., 2014; Seale et al., 2019). Prolactin (Prl) is responsible for a variety of physiological actions in vertebrates including fish, amphibians, reptiles, and mammals (Bern and Nicoll, 1968). In fish, the osmoregulatory function of Prl is well established. Without the pituitary gland, euryhaline fish will not survive in FW unless it has received Prl replacement therapy (Pickford and Phillips, 1959; Dharmamba et al., 1967), a seminal finding that led to the continued characterization of the Prl cell as a model osmoreceptor (Grau and Helms, 1990; Seale et al., 2006; Seale et al., 2020). Prl secretion from the tilapia pituitary responds directly to the extracellular osmolality which it regulates (Grau et al., 1981; Seale et al., 2002). Once released into circulation, Prl acts on a number of osmoregulatory epithelia, such as the kidney, intestine, and gills, to promote ion uptake (Breves et al., 2011; Seale et al., 2014). In peripheral tissues, Prl's actions are largely mediated through the regulation of genes involved in the transport of water and ions, including the $\mathrm{Na}^{+} / \mathrm{Cl}^{-}$cotransporter $(\mathrm{Ncc}), \mathrm{Na}^{+} / \mathrm{K}^{+} / 2 \mathrm{Cl}^{-}$cotransporter (Nkcc), and $\mathrm{Na}^{+} / \mathrm{K}^{+}$-ATPase (Nka) (Breves et al., 2010; Tipsmark et al., 2011; Inokuchi et al., 2015). In gill, the genes encoding these effectors of osmoregulation are also directly regulated by changes in extracellular osmolality (Inokuchi et al., 2015). Inasmuch as osmoregulation is affected by age, we hypothesized that the ability of fish to survive a direct transfer from $\mathrm{FW}$ to SW environment decreases in older animals due to the attenuation of their responsiveness to osmotic and endocrine stimuli. Specifically, we addressed whether there is a difference in the osmotic sensitivity of Prl cells and the osmoregulatory response of gills to Prl between young and old fish.

\section{MATERIALS AND METHODS}

\section{Experimental Animals}

Mozambique tilapia yolk sac fry were collected from broodstock tanks maintained in FW at the Hawaii Institute of Marine Biology (Kaneohe, HI). The fry were kept in 75-l glass aquaria supplied with circulating FW until yolk sac absorption was complete. The fry were then combined into one $75-\mathrm{L}$ aquarium containing $\mathrm{FW}$. Water temperature was maintained at $25 \pm 1^{\circ} \mathrm{C}$ in all tanks. The fish were exposed to a 12L:12D cycle. Fish were fed crushed Silver Cup trout chow (Nelson and Sons, Murray, UT) ad libitum daily, except during both experimental trials, when they were fasted. Prior to survival trials, fish were transferred to outdoor tanks (700l) with a continuous flow of FW at $25 \pm 1^{\circ} \mathrm{C}$ under a natural photoperiod. Tilapia, aged 1, 4, 6, and more than 24 (>24) months (mo), were used for transfer experiments. All experiments were conducted according to the principles and procedures approved by the Institutional Animal Care and Use Committee, University of Hawaii.

\section{Direct Transfer Experiment}

Twenty Mozambique tilapia of each age were kept in four separate tanks containing FW. The approximate average weight of 1-, 4-, 6-, and >24-mo-old fish were $1.0 \pm 0.1,7.5 \pm$ $0.4,26.4 \pm 1.3$, and $278.3 \pm 22.1 \mathrm{~g}$, respectively. At the onset of the experiment, the FW source was shut off and SW (34 ppt) was added to the tanks, such that fish were fully transitioned to full-strength SW by $1 \mathrm{~h}$. Tanks were checked every $30 \mathrm{~min}$ over the following $24 \mathrm{~h}$ to monitor survival.

\section{Rate of Transfer Experiment}

Forty Mozambique tilapia of each age were kept separately in four tanks containing FW. Three FW tanks were switched to SW by adding full-strength SW at different flow rates, taking 1,3, and $12 \mathrm{~h}$ for complete salinity transfers. Survival was monitored for $24 \mathrm{~h}$ following SW transfer by checking the tanks every $2 \mathrm{~h}$.

\section{Effects of Salinity on Branchial Gene Expression}

FW-acclimated fish (mixed sex), aged 4 mo and $>24$ mo, were transitioned to SW over a 12-h period. Control fish were kept in FW for the duration of the experiment. From each of the four experimental tanks, the gill arches of 10 fish were sampled at the end of the $24 \mathrm{~h}$ period following completion of transfer.

\section{Dispersed Prolactin Cell Incubations}

To examine the effects of age on tilapia Prl cell osmosensitivity, we compared hyposmotically-induced $\mathrm{Prl}$ release from dispersed $\mathrm{Prl}$ cells of FW-acclimated tilapia, aged $4 \mathrm{mo}(8.9 \pm 0.6 \mathrm{~g}, n=10)$, and $>24$ mo (307.9 $\pm 22.6 \mathrm{~g}, n=24)$, as previously described (Seale et al., 2012a; Yamaguchi et al., 2018). Briefly, after removal of pituitaries from adult tilapia, rostral pars distalis (RPD) were dissected and pooled in PBS (330 mOsm/kg), diced into pieces, and treated with 
$0.125 \%$ trypsin (Sigma, St. Louis, MO) in PBS. After terminating the trypsin treatment by the addition of trypsin inhibitor $(0.125 \% \mathrm{w} / \mathrm{v}$ in PBS; Sigma), the cells were harvested and cell viability was determined using the trypan blue (Sigma) exclusion test. Cell yield was estimated using a hemocytometer. The cells were then resuspended in $355 \mathrm{mOsm} / \mathrm{kg}$ incubation medium, plated on 96well plates at the density of 16,000 cells/well, and incubated at $26^{\circ} \mathrm{C}$ under saturated humidity. The cells were preincubated for $1 \mathrm{~h}$ in $355 \mathrm{mOsm} / \mathrm{kg}$ medium prior to incubation in hyperosmotic $(355 \mathrm{mOsm} / \mathrm{kg})$ and hyposmotic $(300 \mathrm{mOsm} / \mathrm{kg})$ media. The media samples were collected by $1 \mathrm{~h}$ of incubation and stored at $-20^{\circ} \mathrm{C}$, prior to analysis by radioimmunoassay.

\section{Effects of Prolactin on Cultured Gill Filaments}

To identify direct effects of Prl on branchial gene transcript levels, we cultured filaments from the second and third gill arches of male and female FW-acclimated tilapia, aged 4 mo (10 and $12 \mathrm{~g}$ ) and $>24$ mo (598 and $377 \mathrm{~g}$ ), following Watanabe et al. (2016). Excised gill arches were first washed in sterilized balanced salt solution (BSS: $\mathrm{NaCl} 120 \mathrm{mmol} / \mathrm{l} ; \quad \mathrm{KCl} \quad 4.0 \mathrm{mmol} / \mathrm{l} ; \quad \mathrm{MgSO}_{4}$ $0.8 \mathrm{mmol} / \mathrm{l} ; \mathrm{MgCl}_{2} 1.0 \mathrm{mmol} / \mathrm{l} ; \mathrm{NaHCO}_{3} 2.0 \mathrm{mmol} / \mathrm{l} ; \mathrm{KH}_{2} \mathrm{PO}_{4}$ $0.4 \mathrm{mmol} / \mathrm{l} ; \mathrm{Na}_{2} \mathrm{HPO}_{4} 1.3 \mathrm{mmol} / \mathrm{l} ; \mathrm{CaCl}_{2} 2.1 \mathrm{mmol} / \mathrm{l}$; and Hepes $10 \mathrm{mmol} / \mathrm{l} ; \mathrm{pH} 7.4$ ) and then incubated in $0.025 \% \mathrm{KMnO}_{4}$ for $1 \mathrm{~min}$. After a second wash in BSS, gill filaments of $>24$-mo-old fish were cut in half to minimize the effect of size. In a preliminary experiment, we confirmed that there were no differences in the expression of target genes between whole gill filaments and those cut by half (data not shown). Individual gill filaments were then cut sagittally under a dissecting microscope, and placed in 24-well plates (Becton, Dickinson and Company, Franklin Lake, NJ) containing Leibovitz's L-15 culture medium (Gibco-Thermo Fisher Scientific, Waltham, MA). The culture medium was supplemented with $5.99 \mathrm{mg} / \mathrm{l}$ penicillin and $100 \mathrm{mg} / \mathrm{l}$ streptomycin (Sigma), adjusted to $330 \mathrm{mOsm} / \mathrm{kg}$, and sterilized with a $0.2-\mu \mathrm{m}$ filter. Two gill filaments were placed in each well, which contained $500 \mu$ culture medium supplemented with 0,1 , and $5 \mu \mathrm{g} / \mathrm{ml}$ of ovine Prl (Sigma) $(n=4$ for 4 -mo-old fish and $\mathrm{n}=$ 8 for $>24$-mo-old fish). After overnight incubation $(18 \mathrm{~h})$ at $26^{\circ} \mathrm{C}$, gill filaments were frozen in liquid nitrogen and stored at $-80^{\circ} \mathrm{C}$ prior to RNA extraction and gene expression analyses.

\section{RNA Extraction and Real-Time Quantitative PCR}

For each sample, total RNA was extracted using Tri-Reagent (Molecular Research Center, Cincinnati, $\mathrm{OH}$ ), and then reverse transcribed using a cDNA Reverse Transcription Kit (Applied Biosystems-Thermo Fisher Scientific), according to the manufacturers' protocols. The quantitative real-time PCRs (qRTPCRs) were set up as previously described (Moorman et al., 2014; Inokuchi et al., 2015). Briefly, $200 \mathrm{nmol} / \mathrm{l}$ of each primer, $1 \mu \mathrm{ldDNA}$, and $7.5 \mu \mathrm{l}$ of SYBR Green PCR Master Mix (Applied Biosystems) were added to a $15-\mu$ l final reaction volume. The following cycling conditions were employed for all assays: $2 \mathrm{~min}$ at $50^{\circ} \mathrm{C}, 10 \mathrm{~min}$ at $95^{\circ} \mathrm{C}$ followed by 40 cycles at $95^{\circ} \mathrm{C}$ for $15 \mathrm{~s}$, and $60^{\circ} \mathrm{C}$ for $1 \mathrm{~min}$ using the StepOnePlus Real-Time PCR System (Applied Biosystems). The cycle threshold $(\mathrm{Ct})$ values, mRNA levels of reference, and target genes were determined by the relative quantification method, as specified by StepOne Software v 2.0 (Applied Biosystems). Standard curves were generated from five-fold serial dilutions of cDNA transcribed from gill mRNA samples. The expression levels of target genes were normalized to EFla mRNA levels. Data are expressed as fold-change from FW values of 4-mo-old fish. The primers used are shown in Table $\mathbf{1}$.

\section{Radioimmunoassays}

$\operatorname{Prl}_{188}$ levels in $\operatorname{Prl}$ cell culture medium was measured by homologous RIA as previously described (Ayson et al., 1993; Yada et al., 1994; Yamaguchi et al., 2016), using a primary antibody (antiserum) raised in rabbit against $\operatorname{Prl}_{188}$ (anti$\left.\operatorname{tPrl}_{188}\right)$, and a secondary antibody raised in goat against rabbit IgG (anti-rabbit IgG; Sigma).

\section{Statistical Analysis}

Gene expression of effectors of ion transport from transfer experiments, reported as a fold-change from FW 4-mo-old groups, were analyzed by two-way ANOVA with age and salinity as main effects. Significant $(p<0.05)$ main and interaction effects were followed up with protected Fisher's LSD. $\operatorname{Prl}_{188}$ release from cells incubated in hyposmotic media were expressed as fold-change relative to release from Prl cells incubated in hyperosmotic media, and analyzed by an unpaired $t$ test at each age. The effects of age on branchial mRNA expression in response to oPrl were reported as a fold-change from controls (no added oPrl), and analyzed by two-way ANOVA with age and oPrl treatment as main effects. Significant $(p<0.05)$ main effects of treatment and age were followed up by a Dunnett's test and a t test, respectively. Data are expressed as mean \pm SEM. All statistical analyses were performed using GraphPad Prism 6 (GraphPad, San Diego, CA).

\section{RESULTS}

\section{Effect of Age on Survival Following Salinity Transfer}

There were no survivors aged $>24$ mo by $9.5 \mathrm{~h}$ following transfer from FW to SW. On the other hand, 15, 55, and 100\% of 6-, 4-, and 1-mo-old fish, respectively, survived the salinity transfer by $24 \mathrm{~h}$ (Figure 1A). In a separate trial, when 4-mo-old tilapia were transferred from FW to SW over a 1-, 3-, and 12-h period, 0, 70, and $100 \%$ of the fish survived by $24 \mathrm{~h}$, respectively (Figure 1B). By contrast, the survival rates of fish aged $>24$ mo transferred from FW to SW over a 1-, 3-, and 12-h period were 10, 20, and $90 \%$ by $24 \mathrm{~h}$, respectively (Figure 1C).

\section{Effects of Age on Salinity-Dependent Branchial Gene Expression of Ion Transporters and Pumps}

A two-way ANOVA revealed significant effects of salinity and age on the expression of all genes. Significant interactions were found 
TABLE 1 | Primer sets used in real-time gPCR.

\begin{tabular}{|c|c|c|c|c|}
\hline Gene name & GenBank accession no & & Primer sequence $5^{\prime}$ to $3^{\prime}$ & Efficiency \\
\hline \multirow[t]{2}{*}{ NKAa1a } & LC556924 & Forward & AACTGATTTGGTCCCTGCAA & $114.2 \%$ \\
\hline & & Reverse & ATGCATTTCTGGGCTGTCTC & \\
\hline \multirow[t]{2}{*}{ NKCC1a } & AY513737 & Forward & GGAGGCAAGATCAACAGGATTG & $92.8 \%$ \\
\hline & & Reverse & AATGTCCGAAAAGTCTATCCTGAACT & \\
\hline \multirow[t]{2}{*}{ NCC2 } & EU518934 & Forward & CCGAAAGGCACCCTAATGG & $113.5 \%$ \\
\hline & & Reverse & CTACACTTGCACCAGAAGTGACAA & \\
\hline \multirow[t]{2}{*}{ EF1a } & LC556928 & Forward & AGCAAGTACTACGTGACCATCATTG & $84.6 \%$ \\
\hline & & Reverse & AGTCAGCCTGGGAGGTACCA & \\
\hline
\end{tabular}
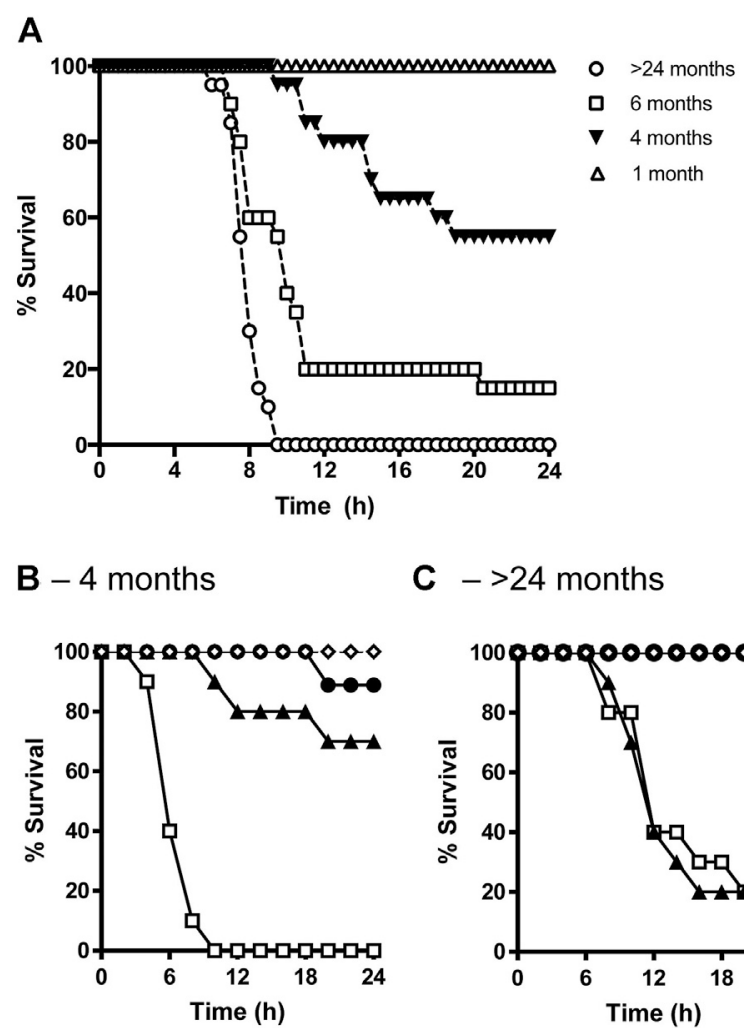

C $->24$ months

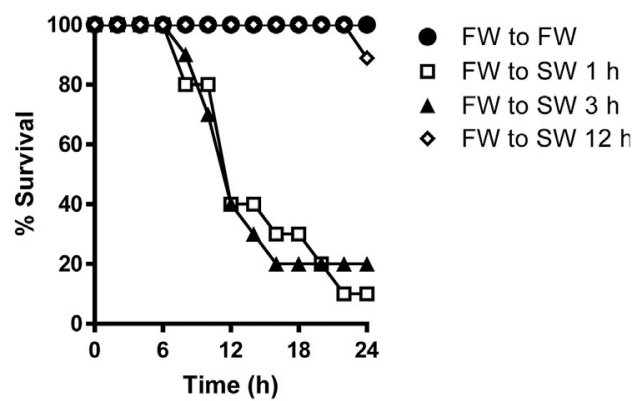

FIGURE 1 | (A) Effects of age on percent survival of tilapia transferred from FW to SW $(n=20)$. Adult tilapia aged 4 months (B) or $>24$ months (C) were then kept in FW (filled circles) or transitioned from FW to SW over a 1-h (open squares), 3-h (filled triangles), and 12-h (open diamonds) period ( $n=10$ ).

in the expression of $n c c 2$ and $n k a \alpha 1 a$ but not in $n k c c 1 a$. The $n c c 2$ expression levels of tilapia aged 4 and $>24$ mo were markedly decreased by $24 \mathrm{~h}$ of transfer from FW to SW. While there was no significant difference between ages in fish acclimated to SW, ncc2 expression was higher in fish aged 4 mo than those aged $>24$ mo (Figure 2A). By contrast, $n k c c 1 a$ expression was upregulated following SW transfer. The rise in $n k c c 1 a$ expression in response to SW transfer was greater in the younger fish, whereas no significant difference was detected between ages in FWacclimated fish (Figure 2B). Similar to the patterns observed

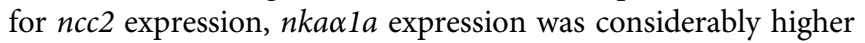
in FW-acclimated 4-mo-old fish when compared with SWacclimated or $>24$-mo-old fish (Figure 2C).

\section{Effects of Age on Hyposmotically Induced Prolactin Release}

Hyposmotically-induced $\operatorname{Prl}_{188}$ release was observed by $1 \mathrm{~h}$ of incubation of dispersed Prl cells from tilapia aged 4 mo but not from those aged $>24$ mo (Figure 3A).

\section{Effect of Ovine Prl on Branchial Expression of ncc2}

We tested the age-dependent transcriptional responses of gill filaments to different concentrations of oPrl over an 18-h incubation period. The expression of $n c c 2$ significantly increased in response to oPrl in a concentration-dependent manner in tilapia 

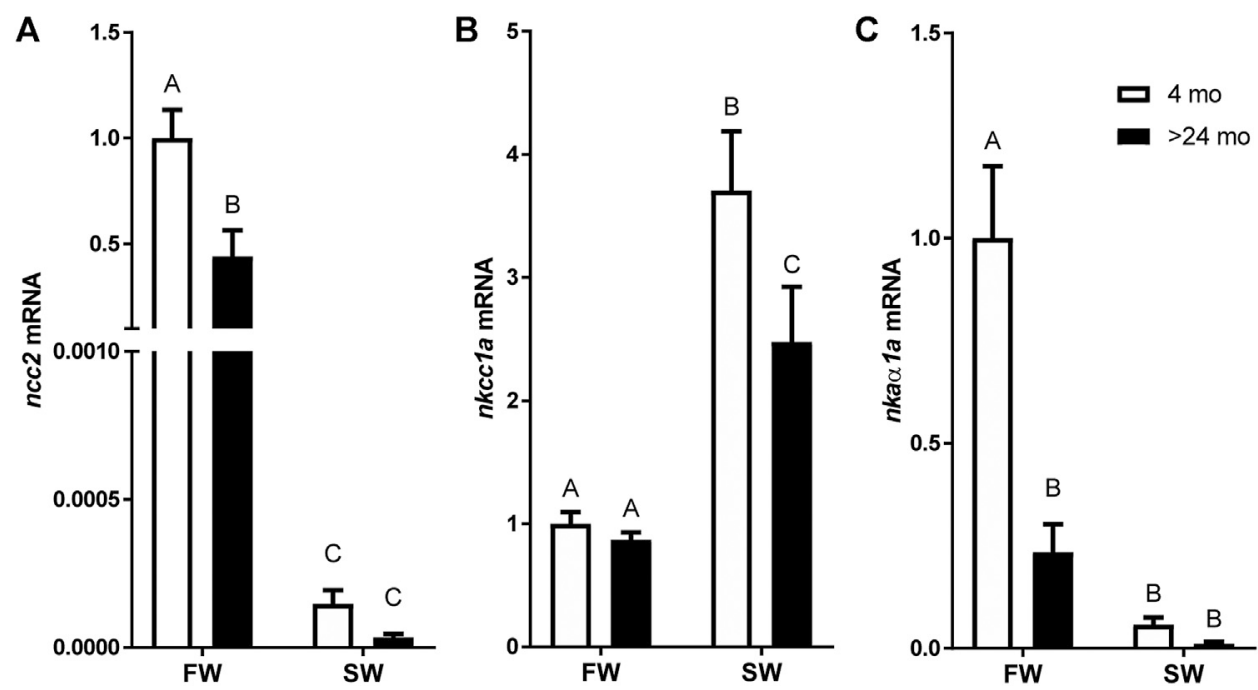

FIGURE 2 | Effects of age and salinity on the expression of branchial mRNA expression of (A) ncc2, (B) $n k c c 1 a$, and (C) $n k a \alpha 1 a$. White and black bars represent means from 4-mo to >24-mo fish. Fish were sampled at the end of the 24-h period following transfer to FW or a 12-h transition to SW. Means not sharing the same letter are significantly different at $p<0.05$.
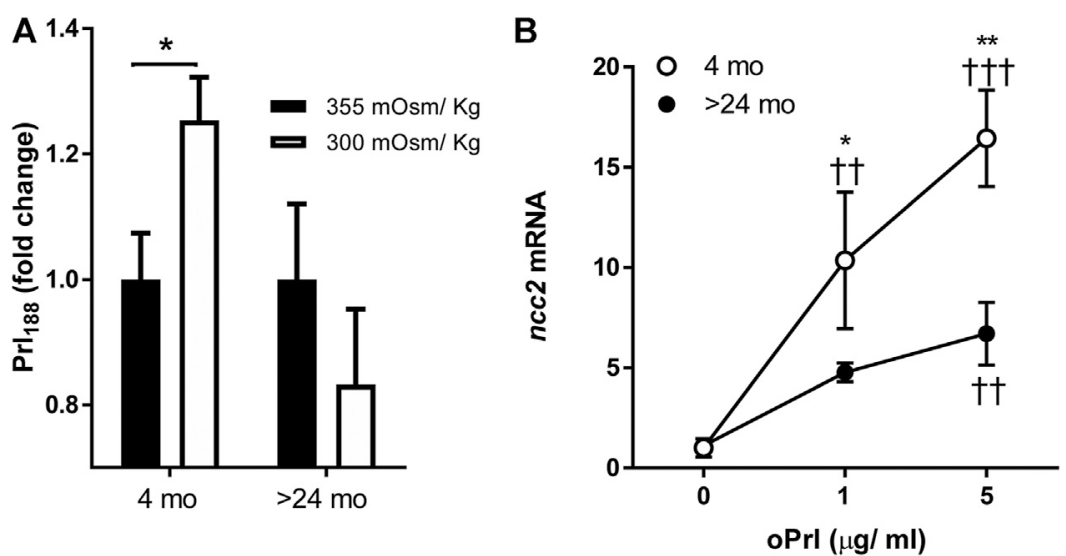

FIGURE 3 | (A) Effects of age (4 months vs > 24 months) on hyposmotically induced $\mathrm{Prl}_{188}$ release from dispersed Prl cells of FW-acclimated fish incubated for $1 \mathrm{~h}$. Black and white bars represent hyperosmotic $(355 \mathrm{mOsm} / \mathrm{kg})$ and hyposmotic $(300 \mathrm{mOsm} / \mathrm{kg})$ media, respectively. * significantly different from each other at $p<0.05$. (B) Effect of oPrl on the expression of ncc2 in gill filaments of FW-acclimated tilapia incubated overnight. Open and filled circles represent means from 4- to $>24$-mo-old

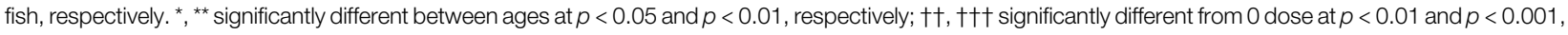
respectively.

of both ages (Figure 3B). The response of 4-mo-old tilapia to oPrl at both concentrations, however, was more robust than that of $>24$ mo-old tilapia. The greatest difference between ages was observed in gill filaments exposed to $5 \mu \mathrm{g} / \mathrm{ml}$ of oPrl; at that concentration, expression of $n c c 2$ was 16.4- and 6.0-fold higher relative to controls in 4 - and >24-mo-old tilapia, respectively.

\section{DISCUSSION}

We characterized the effects of age on salinity tolerance in Mozambique tilapia. The survival rate of tilapia at various ages was examined after rapid $(1 \mathrm{~h})$ and delayed changes in environmental salinity. Overall, the survival rates after direct transfer from FW to SW were inversely related with age (Figure 1A). The results are generally consistent with previous salinity transfer trials, where adults typically require acclimation to an intermediate salinity or a changing salinity regime prior to full transfer to SW (Seale et al., 2002; Moorman et al., 2015). When tilapia were transferred from FW to SW over longer periods, the survival rates were higher in 4-mo-old fish compared with $>24$-mo-old fish by $3 \mathrm{~h}$, indicating that older fish require a longer acclimation period during a salinity challenge (Figures 1B,C). Nevertheless, some discrepancies in 
survival rates of both 4-mo- and $>24$-mo-old fish during the direct transfer $(1 \mathrm{~h})$ from FW and SW were observed between trials. As a direct salinity challenge imparts considerable physiological stress (Wendelaar Bonga, 1977), there could be individual differences in fitness that may account for these discrepancies in survival rates. It is worth noting that Mozambique tilapia grows at slower rates with age, especially $>24$-mo and up to 14 years (Tachihara and Obara, 2003), and the metabolic rate increases in response to a rise in environmental salinity (Zikos et al., 2014). Moreover, unlike mammals, growth in fishes is generally indeterminate as it is largely dependent on environmental conditions (Dutta, 1994). Thus, within a given cohort, body sizes can vary widely, and in turn pose an additional challenge to osmoregulation, especially in smaller fish which have larger surface to volume ratios. In the current trials, despite their smaller size, younger fish had greater tolerance to a rise in salinity, suggesting that the observed decline in salinity tolerance in $>24$ mo-old fish is tied to age rather than size.

Irrespective of body size, plasma osmolality is elevated with increasing salinities, typically rising up to $\sim 440 \mathrm{mOsm} / \mathrm{kg}$ in surviving Mozambique tilapia transferred from FW to brackish water (28-30 ppt), and up to $\sim 550 \mathrm{mOsm} / \mathrm{kg}$ following a direct and lethal transfer to SW (Seale et al., 2012a; Moorman et al., 2015). While baseline plasma osmolalities may vary individually, there are no distinctive patterns across a wide range of body sizes (Moorman et al., 2015; Pavlosky et al., 2019). During a direct oneway transfer from FW to SW, the capacity of Mozambique tilapia to survive becomes largely compromised. Together, both trials indicate that older fish are less capable of recovering a salinity challenge, and require a transition period greater than $3 \mathrm{~h}$ to survive the transfer between FW and SW by $24 \mathrm{~h}$. Because fish sizes typically increase with age, we also compared osmoregulatory processes between fish of different age-groups through in vitro approaches, where tissue quantity can be normalized across body sizes.

To examine whether the age-dependent loss in ability to acclimate to SW was associated with osmoregulatory capacity, gills were sampled from young and old fish that survived the $24-\mathrm{h}$ challenge. In gills, ionocytes are responsible for ion uptake in FW and ion secretion in SW (Evans et al., 2005; Foskett et al., 1983). Active ion secretion in the gill of SW-acclimated fish is mediated by Nkccla in the basolateral membrane of ionocytes (Hwang et al., 2011), whereas ion uptake are largely mediated by Ncc2 in the apical membrane and Nkaala in the basolateral membrane when fish are in FW (Hiroi et al., 2008; Inokuchi et al., 2008; Tipsmark et al., 2011). Consistent with its function in ion uptake, branchial ncc2 and nkax1a expression was higher in FWacclimated fish than those in SW (Figures 2A,C). By contrast, branchial expression of $n k c c 1 a$ was higher in SW fish (Figure 2B). Notably, the relative expression of $n k c c 1 a$, which plays an important role in hyposmoregulation, was significantly upregulated in younger fish after SW transfer. This finding indicates a clear effect of age in the sensitivity of branchial ionocytes. Conversely, salinity-induced transcriptional activation of ion transport was attenuated in older fish facing a SW challenge.
Next, we investigated whether the age of fish affected the capacity of dispersed Prl cells from the RPD of tilapia pituitaries to respond differently to a hyposmotic stimulus. Tilapia Prl cells produce two $\operatorname{Prl}$ molecules: $\operatorname{Prl}_{188}$ and $\operatorname{Prl}_{177}$. $\operatorname{Prl}_{188}$ was measured in this experiment as it is more sensitive to hyposmotic stimuli than $\operatorname{Prl}_{177}$ (Seale et al., 2012a). $\operatorname{Prl}_{188}$ release has been consistently shown to increase in response to a fall in extracellular osmolality in vitro (Dharmamba and Nishioka, 1968; Ingleton et al., 1973; Grau et al., 1981; Richman et al., 1986; Seale et al., 2002; Seale et al., 2012a). In the current study, $\mathrm{Prl}$ cells from 4-mo-old tilapia increased $\operatorname{Prl}_{188}$ release in response to a physiologically relevant hyposmotic stimulus, $300 \mathrm{mOsm} / \mathrm{kg}$, while cells from tilapia aged $>24$ mo did not (Figure 3A). The lack of responsiveness of older tilapia is analogous to the lower osmotic sensitivity of Prl cells of Nile tilapia (O. niloticus), a congener of lower salinity tolerance (Yamaguchi et al., 2018). As a potent hyperosmoregulatory hormone in fish, Prl acts by promoting ion uptake and reducing water permeability in gill (Hirano, 1986). Specifically, oPrl has been shown to upregulate branchial $n c c 2$ and $n k a \alpha 1 a$ in Mozambique tilapia; $n k c c 1 a$ was less responsive to oPrl (Breves et al., 2010; Inokuchi et al., 2015). We focused on ncc2 because it encodes an apical membrane protein that functions to directly absorb ions from environmental water. The concentration-dependent, oPrl-induced upregulation of $n c c 2$ in gill filaments incubated for $18 \mathrm{~h}$ was more pronounced in 4-mo-old tilapia than in $>24$-mo-old fish (Figure $3 B$ ). This result supports the notion that branchial ionocytes loose sensitivity to both osmotic and endocrine stimuli with age.

In conclusion, for the first time, we experimentally addressed the age-related loss in the sensitivity of osmoregulatory transcripts associated with a transfer from FW to SW in an euryhaline teleost. Moreover, the capacity of Prl cells to respond to hyposmotic stimuli and of gill filaments to respond to oPrl in vitro was suppressed in older fish. Our findings indicate that multiple aspects of osmotic homeostasis, from osmoreception to hormonal and environmental control of osmoregulation, appear to decline in direct relation to age and adversely affect the ability of older fish to survive a transfer to hyperosmotic environments. Future studies aimed at comparing different size classes within the same age cohort could further resolve whether there are also size-specific effects on osmoregulatory capacity.

\section{DATA AVAILABILITY STATEMENT}

The datasets presented in this study can be found in online repositories. The names of the repository/repositories and accession number(s) can be found in the article/ Supplementary Material.

\section{ETHICS STATEMENT}

The animal study was reviewed and approved by the Institutional Animal Care and Use Committee, University of Hawaii. 


\section{AUTHOR CONTRIBUTIONS}

MI contributed to the experimental procedures, statistical analysis, writing, and editing of the manuscript. YY and BM contributed to the experimental procedures and editing of the manuscript. AS contributed to the conception and design of this study, statistical analysis, writing, and editing of the manuscript.

\section{FUNDING}

This work was funded in part by grants from the National Science Foundation (IOS-1755016), the National Oceanic and

\section{REFERENCES}

Ayson, F. G., Kaneko, T., Tagawa, M., Hasegawa, S., Grau, E. G., Nishioka, R. S., et al. (1993). Effects of Acclimation to Hypertonic Environment on Plasma and Pituitary Levels of Two Prolactins and Growth Hormone in Two Species of tilapia, Oreochromis mossambicus and Oreochromis niloticus. Gen. Comp. Endocrinol. 89, 138-148. doi:10.1006/gcen.1993.1017

Baylis, P. H. (1987). Osmoregulation and Control of Vasopressin Secretion in Healthy Humans. Am. J. Physiology-Regulatory, Integr. Comp. Physiol. 253, R671-R678. doi:10.1152/ajpregu.1987.253.5.R671

Bern, H. A., and Nicoll, C. S. (1968). The Comparative Endocrinology of Prolactin. Recent Prog. Horm. Res. 24, 681-720. doi:10.1016/b978-1-48319827-9.50019-8

Bourque, C. W., and Oliet, S. H. (1997). Osmoreceptors in the central Nervous System. Annu. Rev. Physiol. 59, 601-619. doi:10.1146/annurev.physiol.59.1.601

Breves, J. P., Seale, A. P., Helms, R. E., Tipsmark, C. K., Hirano, T., and Grau, E. G. (2011). Dynamic Gene Expression of GH/PRL-family Hormone Receptors in Gill and Kidney during Freshwater-Acclimation of Mozambique tilapia. Comp. Biochem. Physiol. A: Mol. Integr. Physiol. 158, 194-200. doi:10.1016/j.cbpa. 2010.10.030

Breves, J. P., Watanabe, S., Kaneko, T., Hirano, T., and Grau, E. G. (2010). Prolactin Restores Branchial Mitochondrion-Rich Cells Expressing $\mathrm{Na}+\mathrm{Cl}-$ Cotransporter in Hypophysectomized Mozambique tilapia. Am. J. Physiology-Regulatory, Integr. Comp. Physiol. 299, R702-R710. doi:10. 1152/ajpregu.00213.2010

Dharmamba, M., Handin, R. I., Nandi, J., and Bern, H. A. (1967). Effect of Prolactin on Freshwater Survival and on Plasma Osmotic Pressure of Hypophysectomized Tilapia Mossambica. Gen. Comp. Endocrinol. 9, 295-302. doi:10.1016/0016-6480(67)90064-0

Dharmamba, M., and Nishioka, R. S. (1968). Response of "Prolactin-Secreting" Cells of Tilapia Mossambica to Environmental Salinity. Gen. Comp. Endocrinol. 10, 409-420. doi:10.1016/0016-6480(68)90051-8

Dmitrieva, N. I., and Burg, M. B. (2007). High NaCl Promotes Cellular Senescence. Cell Cycle 6, 3108-3113. doi:10.4161/cc.6.24.5084

Dmitrieva, N. I., and Burg, M. B. (2011). Increased Insensible Water Loss Contributes to Aging Related Dehydration. PLoS One 6, e20691. doi:10. 1371/journal.pone.0020691

Dutta, H. (1994). Growth in Fishes. Gerontology 40 (2-4), 97-112. doi:10.1159/ 000213581

Evans, D. H., Piermarini, P. M., and Choe, K. P. (2005). The Multifunctional Fish Gill: Dominant Site of Gas Exchange, Osmoregulation, Acid-Base Regulation, and Excretion of Nitrogenous Waste. Physiol. Rev. 85, 97-177. doi:10.1152/ physrev.00050.2003

Foskett, J. K., Bern, H. A., Machen, T. E., and Conner, M. (1983). Chloride Cells and the Hormonal Control of Teleost Fish Osmoregulation. J. Exp. Biol. 106, 255-281. doi:10.1242/jeb.106.1.255

Grau, E. G., and Helms, L. M. (1990). The tilapia Prolactin Cell-TtwentyFfive Years of Investigation. Prog. Clin. Biol. Res. 342, 534-540 .

Grau, E. G., Nishioka, R. S., and Bern, H. A. (1981). Effects of Osmotic Pressure and Calcium Ion on Prolactin Release In Vitro from the Rostral Pars Distalis of the
Atmospheric Administration (NA18OAR4170347), the National Institutes of Diabetes and Digestive and Kidney Diseases 1R21DK111775-01 from the National Institutes of Health, and the National Institute of Food and Agriculture Hatch no. HAW02051-H to AS. The views expressed herein are those of the authors and do not necessarily reflect the views of the aforementioned granting agencies.

\section{ACKNOWLEDGMENTS}

We are also grateful to the Hawaii Institute of Marine Biology.

tilapia Sarotherodon Mossambicus. Gen. Comp. Endocrinol. 45, 406-408. doi:10. 1016/0016-6480(81)90082-4

Grau, E. G., Richman, N. H., III, and Borski, R. J. (1994). "Osmoreception and a Simple Endocrine Reflex of the Prolactin Cell of the tilapia Oreochromis mossambicus," in Perspectives Comp. Endocrinol. Editors K.G. Davey, R.E. Peter, and S.S. Tobe (National Research Council of Canada, Ottawa), 251-256.

Hirano, T. (1986). The Spectrum of Prolactin Action in Teleosts. Prog. Clin. Biol. Res. 205, 53-74

Hiroi, J., Yasumasu, S., McCormick, S. D., Hwang, P.-P., and Kaneko, T. (2008). Evidence for an Apical Na-Cl Cotransporter Involved in Ion Uptake in a Teleost Fish. J. Exp. Biol. 211, 2584-2599. doi:10.1242/jeb.018663

Hwang, P.-P., Lee, T.-H., and Lin, L.-Y. (2011). Ion Regulation in Fish Gills: Recent Progress in the Cellular and Molecular Mechanisms. Am. J. PhysiologyRegulatory, Integr. Comp. Physiol. 301, R28-R47. doi:10.1152/ajpregu.00047. 2011

Ingleton, P. M., Baker, B. I., and Ball, J. N. (1973). Secretion of Prolactin and Growth Hormone by Teleost Pituitariesin Vitro. J. Comp. Physiol. 87, 317-328. doi:10.1007/bf00695266

Inokuchi, M., Breves, J. P., Moriyama, S., Watanabe, S., Kaneko, T., Lerner, D. T., et al. (2015). Prolactin 177, Prolactin 188, and Extracellular Osmolality Independently Regulate the Gene Expression of Ion Transport Effectors in Gill of Mozambique tilapia. Am. J. Physiology-Regulatory, Integr. Comp. Physiol. 309, R1251-R1263. doi:10.1152/ajpregu.00168.2015

Inokuchi, M., Hiroi, J., Watanabe, S., Lee, K. M., and Kaneko, T. (2008). Gene Expression and Morphological Localization of NHE3, NCC and NKCCla in Branchial Mitochondria-Rich Cells of Mozambique tilapia (Oreochromis mossambicus) Acclimated to a Wide Range of Salinities. Comp. Biochem. Physiol. Part A: Mol. Integr. Physiol. 151, 151-158. doi:10.1016/j.cbpa.2008. 06.012

Jeffries, K. M., Hinch, S. G., Donaldson, M. R., Gale, M. K., Burt, J. M., Thompson, L. A., et al. (2011). Temporal Changes in Blood Variables during Final Maturation and Senescence in Male Sockeye salmon Oncorhynchus nerka: Reduced Osmoregulatory Ability Can Predict Mortality. J. Fish. Biol. 79, 449-465. doi:10.1111/j.1095-8649.2011.03042.x

Kenney, W. L., and Chiu, P. (2001). Influence of Age on Thirst and Fluid Intake. Med. Sci. Sports Exerc. 33, 1524-1532. doi:10.1097/00005768-200109000-00016

Lee, Y., Lee, M., and Chang, K. Y. (1998). Studies on the Activation of Neurons Involved in Osmoregulation in Developing and Aging Rat. Korean J. Anat. 31, 319-326.

Mack, G. W., Weseman, C. A., Langhans, G. W., Scherzer, H., Gillen, C. M., and Nadel, E. R. (1994). Body Fluid Balance in Dehydrated Healthy Older Men: Thirst and Renal Osmoregulation. J. Appl. Physiol. 76, 1615-1623. doi:10.1152/ jappl.1994.76.4.1615

Moorman, B. P., Inokuchi, M., Yamaguchi, Y., Lerner, D. T., Grau, E. G., and Seale, A. P. (2014). The Osmoregulatory Effects of Rearing Mozambique tilapia in a Tidally Changing Salinity. Gen. Comp. Endocrinol. 207, 94-102. doi:10.1016/j. ygcen.2014.03.013

Moorman, B. P., Lerner, D. T., Grau, E. G., and Seale, A. P. (2015). The Effects of Acute Salinity Challenges on Osmoregulation in Mozambique tilapia Reared in a Tidally Changing Salinity. J. Exp. Biol. 218, 731-739. doi:10.1242/jeb.112664 
O’Neill, P. A., and McLean, K. A. (1992). Water Homeostasis and Ageing. Med. Lab. Sci. 49, 291-298.

Pavlosky, K. K., Yamaguchi, Y., Lerner, D. T., and Seale, A. P. (2019). The Effects of Transfer from Steady-State to Tidally-Changing Salinities on Plasma and Branchial Osmoregulatory Variables in Adult Mozambique tilapia. Comp. Biochem. Physiol. Part A: Mol. Integr. Physiol. 227, 134-145. doi:10.1016/j. cbpa.2018.10.005

Pickford, G. E., and Phillips, J. G. (1959). Prolactin, a Factor in Promoting Survival of Hypophysectomized Killifish in Fresh Water. Science 130, 454-455. doi:10. $1126 /$ science.130.3373.454

Pomatto, L. C. D., and Davies, K. J. A. (2017). The Role of Declining Adaptive Homeostasis in Ageing. J. Physiol. 595, 7275-7309. doi:10.1113/JP275072

Richman, N. H., Ford, C. A., Grau, E. G., and Cooke, I. M. (1986). The Effects of Osmotic Pressure and High $\left[\mathrm{K}^{+}\right]$on Prolactin (PRL) Release and $\mathrm{Ca}^{2+}$ Efflux from tilapia Rostral Pars Distalis (RPD) in Perifusion Culture. Amer. Zool. 26, $144 \mathrm{~A}$.

Robertson, G. L., and Rowe, J. (1980). The Effect of Aging on Neurohypophyseal Function. Peptides 1, 159-162. doi:10.1016/0196-9781(80)90113-8

Rolls, B. J., and Phillips, P. A. (1990). Aging and Disturbances of Thirst and Fluid Balance. Nuutr. Rev. 48, 137-144. doi:10.1111/j.1753-4887.1990.tb02915.x

Seale, A. P., Hirano, T., and Grau, E. G. (2006). "Osmoreception: a Fish Model for a Fundamental Sensory Modality," in Fish Endocrinology. Editor G. Zaccone (Enfield: Science Publishers), 419-440.

Seale, A. P., Malintha, G. H. T., Celino-Brady, F. T., Head, T., Belcaid, M., Yamaguchi, Y., et al. (2020). Transcriptional Regulation Ofprolactinin a Euryhaline Teleost: Characterisation of Gene Promoters through In Silico and Transcriptome Analyses. J. Neuroendocrinol. 32, e12905. doi:10.1111/ jne. 12905

Seale, A. P., Moorman, B. P., Stagg, J. J., Breves, J. P., Lerner, D. T., and Grau, E. G. (2012a). Prolactin177, Prolactin188 and Prolactin Receptor 2 in the Pituitary of the Euryhaline tilapia, Oreochromis mossambicus, Are Differentially Osmosensitive. J. Endocrinol. 213, 89-98. doi:10.1530/joe-11-0384

Seale, A. P., Pavlosky, K. K., Celino-Brady, F. T., Yamaguchi, Y., Breves, J. P., and Lerner, D. T. (2019). Systemic versus Tissue-Level Prolactin Signaling in a Teleost during a Tidal Cycle. J. Comp. Physiol. B 189, 581-594. doi:10.1007/ s00360-019-01233-9

Seale, A. P., Stagg, J. J., Yamaguchi, Y., Breves, J. P., Soma, S., Watanabe, S., et al. (2014). Effects of Salinity and Prolactin on Gene Transcript Levels of Ion Transporters, Ion Pumps and Prolactin Receptors in Mozambique tilapia Intestine. Gen. Comp. Endocrinol. 206, 146-154. doi:10.1016/j.ygcen.2014. 07.020

Seale, A. P., Watanabe, S., and Grau, E. G. (2012b). Osmoreception: Perspectives on Signal Transduction and Environmental Modulation. Gen. Comp. Endocrinol. 176, 354-360. doi:10.1016/j.ygcen.2011.10.005

Seale, A., Riley, L., Leedom, T., Kajimura, S., Dores, R., Hirano, T., et al. (2002). Effects of Environmental Osmolality on Release of Prolactin, Growth Hormone and ACTH from the tilapia Pituitary. Gen. Comp. Endocrinol. 128, 91-101. doi:10.1016/S0016-6480(02)00027-8

Tachihara, K., and Obara, E. (2003). Age and Growth of the Mozambique tilapia, Oreochromis mossambicus Introduced into the Genka River on Okinawa Island. Aquacult. Sci. 51, 307-313. doi:10.11233/aquaculturesci1953.51.307
Takei, Y., Hiroi, J., Takahashi, H., and Sakamoto, T. (2014). Diverse Mechanisms for Body Fluid Regulation in Teleost Fishes. Am. J. Physiology-Regulatory, Integr. Comp. Physiol. 307, R778-R792. doi:10.1152/ajpregu.00104.2014

Thunhorst, R. L., Beltz, T. G., and Johnson, A. K. (2010). Drinking and Arterial Blood Pressure Responses to ANG II in Young and Old Rats. Am. J. PhysiologyRegulatory, Integr. Comp. Physiol. 299, R1135-R1141. doi:10.1152/ajpregu. 00360.2010

Thunhorst, R. L., Grobe, C. L., Beltz, T. G., and Johnson, A. K. (2011). Effects of $\beta$-adrenergic Receptor Agonists on Drinking and Arterial Blood Pressure in Young and Old Rats. Am. J. Physiology-Regulatory, Integr. Comp. Physiol. 300, R1001-R1008. doi:10.1152/ajpregu.00737.2010

Tipsmark, C. K., Breves, J. P., Seale, A. P., Lerner, D. T., Hirano, T., and Grau, E. G. (2011). Switching of Na+, K+-ATPase Isoforms by Salinity and Prolactin in the Gill of a Cichlid Fish. J. Endocrinol. 209, 237-244. doi:10.1530/JOE-10-0495

Watanabe, S., Itoh, K., and Kaneko, T. (2016). Prolactin and Cortisol Mediate the Maintenance of Hyperosmoregulatory Ionocytes in Gills of Mozambique tilapia: Exploring with an Improved Gill Incubation System. Gen. Comp. Endocrinol. 232, 151-159. doi:10.1016/j.ygcen.2016.04.024

Wendelaar Bonga, S. E. (1997). The Stress Response in Fish. Physiol. Rev. 77, 591-625. doi:10.1152/physrev.1997.77.3.591

Yada, T., Hirano, T., and Grau, E. G. (1994). Changes in Plasma Levels of the Two Prolactins and Growth Hormone during Adaptation to Different Salinities in the Euryhaline Tilapia, Oreochromis mossambicus. Gen. Comp. Endocrinol. 93, 214-223. doi:10.1006/gcen.1994.1025

Yamaguchi, Y., Breves, J. P., Haws, M. C., Lerner, D. T., Grau, E. G., and Seale, A. P. (2018). Acute Salinity Tolerance and the Control of Two Prolactins and Their Receptors in the Nile tilapia (Oreochromis niloticus) and Mozambique tilapia (O. mossambicus): A Comparative Study. Gen. Comp. Endocrinol. 257, 168-176. doi:10.1016/j.ygcen.2017.06.018

Yamaguchi, Y., Moriyama, S., Lerner, D. T., Grau, E. G., and Seale, A. P. (2016). Autocrine Positive Feedback Regulation of Prolactin Release from tilapia Prolactin Cells and its Modulation by Extracellular Osmolality. Endocrinology 157, 3505-3516. doi:10.1210/en.2015-1969

Zikos, A., Seale, A. P., Lerner, D. T., Grau, E. G., and Korsmeyer, K. E. (2014), Effects of Salinity on Metabolic Rate and Branchial Expression of Genes Involved in Ion Transport and Metabolism in Mozambique tilapia (Oreochromis mossambicus). Comp. Biochem. Physiol. Part A: Mol. Integr. Physiol. 178, 121-131. doi:10.1016/j.cbpa.2014.08.016

Conflict of Interest: The authors declare that the research was conducted in the absence of any commercial or financial relationships that could be construed as a potential conflict of interest.

Copyright $\odot 2021$ Inokuchi, Yamaguchi, Moorman and Seale. This is an open-access article distributed under the terms of the Creative Commons Attribution License (CC $B Y)$. The use, distribution or reproduction in other forums is permitted, provided the original author(s) and the copyright owner(s) are credited and that the original publication in this journal is cited, in accordance with accepted academic practice. No use, distribution or reproduction is permitted which does not comply with these terms. 